Published Title: RESIDENTIAL ENERGY ENVIRONMENTAL

KUZNETS CURVE EXTENDED WITH NON-LINEAR TEMPERATURE

EFFECTS: A QUANTILE REGRESSION FOR ANDALUSIAN (SPAIN)

MUNICIPALITIES

Preprint Title: RESIDENTIAL ENERGY ENVIRONMENTAL KUZNETS CURVE AND NON-LINEAR TEMPERATURE EFFECTS: A QUANTILE REGRESSION FOR ANDALUSIAN MUNICIPALITIES

\author{
María del P. Pablo-Romero ${ }^{\text {a* }}$, Rafael Pozo-Barajas ${ }^{\text {b }}$, Guillermo Molleda Jimena ${ }^{\text {b }}$ \\ * Corresponding author
}

a. Department of Economic Analysis and Political Economy, Faculty of Economics and Business Sciences, Universidad de Sevilla, Ramon y Cajal 1, 41018, Seville, Spain

b Department of Financial Economy and Operations Management, Faculty of Economics and Business Sciences, Universidad de Sevilla, Ramon y Cajal 1, 41018, Seville, Spain

\title{
Abstract
}

The increased use of renewable energy in electricity generation has not been sufficient to reduce the associated emissions. Therefore, a better understanding of the evolution of electricity consumption may be advisable to undertake suitable energy policies. This paper contributes to this understanding by analyzing the non-linear income and temperature effects on electricity demand in the residential sector in Andalusia (Spain). To this end, panel data Ordinary Least Squares and quantile regression analysis methods have been performed to provide a complete picture of the relationship between the studied variables. The results show evidence to support an inverted $\mathrm{N}$ shaped 
relationship, with respect to income, without reaching the upper threshold point. The results also show that electricity elasticity, with respect to income, tends to increase with residential electricity consumption. It is also observed that temperature values, increasing above $22^{\circ} \mathrm{C}$ and temperatures decreasing below $15^{\circ} \mathrm{C}$, progressively increase residential electricity consumption, the elasticity with respect to temperatures being higher for municipalities with lower residential electricity consumption. Reinforcing energy efficiency measures in the municipalities with the highest electricity consumption is recommended.

Keywords. Residential energy; Environmental Kuznets curve; Temperature effects; Quantile regression; Andalusia 


\title{
RESIDENTIAL ENERGY ENVIRONMENTAL KUZNETS CURVE AND \\ NON-LINEAR TEMPERATURE EFFECTS: A QUANTILE REGRESSION FOR ANDALUSIAN MUNICIPALITIES
}

\begin{abstract}
The increased use of renewable energy in electricity generation has not been sufficient to reduce the associated emissions. Therefore, a better understanding of the evolution of electricity consumption may be advisable to undertake suitable energy policies. This paper contributes to this understanding by analyzing the non-linear income and temperature effects on electricity demand in the residential sector in Andalusia (Spain). To this end, panel data ordinary least square and quantile regression analysis methods have been performed to provide a complete picture of the relationship between the studied variables. The results show evidence to support an inverted $\mathrm{N}$ shaped relationship, with respect to income, without reaching the upper threshold point. The results also show that electricity elasticity, with respect to income, tends to increase with residential electricity consumption. It is also observed that temperature values, increasing above $22^{\circ} \mathrm{C}$ and temperatures decreasing below $15^{\circ} \mathrm{C}$, progressively increase residential electricity consumption, the elasticity with respect to temperatures being higher for municipalities with lower residential electricity consumption. Reinforcing energy efficiency measures in the municipalities with the highest electricity consumption is recommended.
\end{abstract}

Keywords. Residential energy; Environmental Kuznets curve; Temperature effects; Quantile regression; Andalusia 


\section{RESIDENTIAL ENERGY ENVIRONMENTAL KUZNETS CURVE AND \\ NON-LINEAR TEMPERATURE EFFECTS: A QUANTILE REGRESSION FOR ANDALUSIAN MUNICIPALITIES}

\section{Introduction}

The IPCC (2018) report warns of the impacts of global warming. The report indicates that, in order to not exceed the temperature increase of $1.5^{\circ} \mathrm{C}, \mathrm{CO}_{2}$ emissions should decrease $45 \%$ by 2030, compared to 2010 levels, and be equal to zero by around 2050 . In order to achieve these targets, fast and powerful transitions are needed in the energy, land, urban and industrial systems. Changes in energy systems are crucial, as energy is responsible for two thirds of GHG and $80 \%$ of $\mathrm{CO}_{2}$ emissions (IEA, 2015).

All energy sectors are relevant to the reduction of $\mathrm{CO}_{2}$ emissions. However, the electricity sector has special relevance. It can be inferred from the IPCC (2018) report that, to limit global warming, it is required to limit the use of energy by means of greater energy efficiency and have a trend towards electrification. Likewise, the report considers it will be necessary for renewable energies to contribute $70-85 \%$ of electricity in 2050. According to the U.S. Energy Information Administration report (EIA, 2019), the use of renewable for electricity generation augmented by over 7\%, in 2018. Nevertheless, the increase in electricity demand has been higher than the increased use of renewable energy in the sector, in absolute terms. Therefore, in addition to the analysis of electricity production, analysis related to the evolution of electricity consumption is also relevant, in order to define policies aimed at achieving the national targets. 
Some considerations could be related to this increased electricity demand. Firstly, the residential sector is one of the most relevant in explaining increased electricity demand (IEA, 2019). Secondly, weather conditions could explain part of the increased electricity demand (IEA, 2019). Additionally, it is worth pointing out that, according to the IPCC report (2018), not only is an increase in temperatures expected, but also an increase in extreme temperatures, especially in mid-latitude countries. Therefore, this temperature change could also be associated with increased electricity demand. Finally, it is worth noting that income evolution may condition the electricity demand, especially residential electricity demand (Narayan and Doytch, 2017). In addition, the relationship has recently been considered to be non-linear, which has led to testing the residential Energy-EKC (Pablo-Romero et al., 2017; Pablo-Romero and Sánchez-Braza, 2019; Raza et al., 2020).

Based on these considerations, the aim of this study is to analyze the increase in electricity consumption in the residential sector in Andalusia (Spain), by considering the non-linear income and temperature effects. Considering non-linear income effects allows the Energy-EKC hypothesis for the residential electricity sector to be compared, while consideration of non-linear temperature effects allows evaluation of extreme temperature effects on the electricity demand. To this end, panel data techniques referring to the Andalusian municipalities, for the period 2001-2016, were used. Specifically, the quantile regression analysis method was performed to determine whether income and temperatures have different impacts, across conditional quantiles of residential electricity consumption, therefore providing a complete picture of the relationship between the studied variables. Thus, the results of this paper can help to design energy policy measures, aimed at achieving the Andalusia and Spanish national targets, related to energy and emissions. 
This analysis is especially interesting within a global warming framework. The available estimates indicate that electricity consumption will be affected by temperature increases (Ministerio de Medio Ambiente, 2006), with the warmest territories being the most affected (Burke et al., 2015). In this sense, Spain is a country that is highly vulnerable to global warming, and this is especially true in Andalusia as it is an area where temperature increases are expected to be higher than the European average (European Environment Agency, 2017). Furthermore, taking municipalities as a territorial frame of reference is more appropriate than taking broader territorial areas. The municipal scope allows the use of more accurate temperature data, without the need to use territorial averages. By taking Andalusia as the frame of reference for the study, temperatures can be taken locally, making the study more accurate.

The structure of this paper is as follows. After the introduction, Section 2 a 3 present the literature review and the databases used, respectively. Section 4 describes the methodology used. Section 5 presents the results and discussion. Finally, Section 6 concludes.

\section{Literature review}

Two main previous research lines are specifically associated with this study. The first is the analysis of the Energy-EKC hypothesis. The second is related to the analysis of the temperature effects on energy consumption.

\subsection{The Energy-EKC hypothesis}

The seminal paper by Kraft and Kraft (1978) was the first to study the relationship between energy consumption and economic growth. Since then, other researchers have made in-depth studies of these relationships, mostly showing that energy consumption is positively affected by economic growth. A review of these studies can be found in Tiba 
and Omri (2017). Some of these studies delved into the type of relationship that exists between income and energy consumption, showing that a non-linear relationship better explains the relationship between the variables.

Based on the so-called EKC that defines a non-linear relationship between emissions and income, some researchers have adopted the Energy-EKC term to confirm whether an inverted $U$ shape may explain the energy consumption and income relationships (Dong and Hao, 2018). Among them, some studies, such as those by Nguyen-Van (2010), Sbia et al. (2017) and Dong and Hao (2018), support the Energy-EKC hypothesis, while others, such as those by Zilio and Recalde (2011) and Pablo-Romero and De Jesús (2016), do not. However, they all seem to agree that a non-linear relationship between the energy consumption and income better explains the link between them.

Following the line of these studies, some researchers have focused on the studies of the non-linear relationship, between residential energy consumption and income, by testing the Energy-EKC. Among these studies may be cited those by Pablo-Romero and Sánchez-Braza (2017) and Borozan (2018) for the EU countries, the study by PabloRomero et al. (2019) for the transition economies, and the study by Raza et al. (2020) for Next-11 and BRICS countries. Likewise, for households, the Energy-EKC has been tested in studies by Lenzen et al. (2006), for Australia, Brazil, Denmark, India and Japan, and Volland (2017) for the United Kingdom among others. However, to our knowledge, there is no residential Energy-EKC study for Spain as a whole, or for areas within Spain.

These studies have been improving the econometric estimates procedures, and recent residential Energy-EKC analyses use quantile regression or panel quantile regressions to take into account how heterogeneity affects the results, such as the studies by 
Borozan (2019) and Tilov et al. (2020). These papers allow the relationships between energy consumption and income in the residential sector to be analyzed, differentiating by energy quantiles.

\subsection{Electricity consumption and temperature effects}

Many econometric analyses of energy demand have been incorporating temperature as an explanatory variable. The review carried out by Auffhammer and Mansur (2014) shows that these studies are mostly microeconomic, based on the study of household electricity consumption. However, recently, macroeconomic studies including temperature effects have also been carried out. Among them, some studies analyze the energy consumption of the residential sector. Along this line, it is worth pointing out the studies by Auffhammer (2018), Nie et al. (2018) and Borozan (2019).

The introduction of temperatures into residential energy demand studies has been carried out in different ways. Fazeli et al. (2016) conducted a review of the models used, indicating that Cooling Degree Days (CDD) and the Heating Degree Days (HDD) variables are most often used. These variables are regularly used in those studies for which there is daily data and sufficient information, replacing these at other times with annual, monthly or other average temperatures. Thus, for example, in the recent study by Borozan (2019), a dummy variable referring only to HDD is used, as no CDD were available for the countries studied.

Referring to those studies that simultaneously use HDD and CDD, Fazeli et al, (2016) point out that linear functions are mostly used to determine the impact of temperatures on energy consumption. These linear relationships are often defined either through $\mathrm{V}$ behavior, as for example in Labriet et al. (2013) or by linear V behavior, with a zone where no cooling or heating is required, as for example, in Eskeland and Mideksa (2010). Nevertheless, Fazeli et al. (2016) also point out that recently other studies have 
been considering that the CDD and HDD effects on energy consumption may be nonlinear. In this sense, the authors indicate that these non-linear models are more sensitive to climate than linear models.

Focusing on Spain, there are few studies analyzing the temperature effects on residential energy use. The study by Blázquez et al. (2013) analyzes the residential demand for electricity by using panel data referred to Spanish provinces from 2000 to 2008. In these studies, linear V-shaped models with, and without, a comfort zone are selected to determine the temperature effects. Likewise, the paper by Romero-Jordán et al. (2014), analyses the household electricity consumption in Spain by using a linear V-shaped model with a comfort zone. Finally, the study by Labandeira et al. (2012), analyses the income and price electricity demand elasticity, for Spanish household, by using nonlinear CDD and HDD effects. Specifically, CDD and HDD squared are additionally included in the equation model.

Taking into account the previous studies, this study tests the residential Energy-EKC for Andalusia (Spain). A cubic income specification is used to analyze the non-linear income effect. Therefore, this study enlarges the existing residential Energy-EKC literature by studying a non-linear relationship between electricity demand and economic growth. Additionally, in this study, panel quantile regressions are used to take into account how heterogeneity affects the results when differentiating by energy quantiles. Therefore, this paper enlarges also the previous literature on residential Energy-EKC by using panel quantile regressions. To date, there are few studies using this method in the energy demand functions and, to our knowledge, only two referred to Energy-EKC and none referred to the Spanish economy. Finally, this study analyses the residential Energy-EKC by including temperature effects in the model through the CDD and HDD variables. Therefore, this study enlarges on previous literature related to 
temperature effects on residential energy consumption. To our knowledge, only the study by Tilov et al. (2019), analyzes the CDD and HDD effects on household energy demand, by differentiating by quantiles, but uses a linear specification. On the contrary, in this study, a non-linear CDD and HDD effect is considered, allowing changing by energy quantiles. To our knowledge, this is a novel approach.

\section{Data}

Data came from a variety of databases. The crossing of these databases allows us to obtain enough information on residential electricity consumption, temperature values and income in 513 Andalusia municipalities (Spain), for the 2001 to 2016 period. The municipalities included in the study represent nearly $70 \%$ of total Andalusia municipalities, and more than $80 \%$ of total population in Andalusia. Therefore, data can be considered representative of this region. Specifically, the following data have been used.

\subsection{Residential electricity consumption data}

The Andalusia SIMA database (SIMA, 2020) offers data on electricity demand for most Andalusian municipalities, from 2000 to 2016. Data are divided by sectors. In this study residential electricity consumption data are used. Figures are in $\mathrm{MWh}$, which have been converted into per capita logarithm values, by using the SIMA data related to population.

\subsection{Income data}

Income data also come from SIMA (2020). This database provides data on the declared average income in each Andalusian municipality and is produced from personal income taxes declarations. In this study, these data are considered as a proxy for the income variable, as in Pablo-Romero et al. (2016), and Exposito et al. (2019). Data are 
expressed in 2010 constant euros, their values being converted into logarithms expressed in per capita terms.

\subsection{Temperature variables data}

Temperature variables are used to control for the effect of income on residential energy use. In this paper, the CDD and HDD variables have been introduced in the model.

The CDD and HDD value for each municipality and year are calculated as the sum of the $365 \mathrm{CDD}$ and HDD values, respectively. To calculate these variables the following expressions are used:

$$
\mathrm{CDDi}=(1-\gamma)(\mathrm{Ti}-\mathrm{Tb}) \text { and HDDi }=(1-\gamma)(\mathrm{Tb}-\mathrm{Ti}) \text {. }
$$

$T i$ is the average temperature observed in each municipality and $T b$ is a reference temperature value. According to Pablo-Romero et al. (2019), $\mathrm{Tb}$ is equal to $22^{\circ} \mathrm{C}$ for cooling and $15^{\circ} \mathrm{C}$ for heating, therefore a V-shaped model with a comfort zone is used. Finally, $\gamma$ can be equal to 0 or 1 . In the case of the $\mathrm{CDD}$ variable, $\gamma$ is 0 if $\mathrm{Ti}>\mathrm{Tb}$ and 1 if $\mathrm{Ti}<\mathrm{Tb}$. In the case of the HDD variable, $\gamma$ is 0 if $\mathrm{Ti}<\mathrm{Tb}$ and 1 if $\mathrm{Ti}>\mathrm{Tb}$.

The daily average temperature values for each municipality used to calculate the CDD and HDD values came from three different databases. The first is the Red de Estaciones Agroclimáticas de la Junta de Andalucía (REA, 2020), which offers information from 121 stations. The second is from Agencia Estatal de Meteorología (AEMET, 2020), which offers information for 291 Spanish meteorological stations, including 50 in Andalusia. Finally, the Red de Alerta e Información Fitosanitaria de la Junta de Andalucía (RAIF, 2020) offers information for 80 stations in Andalusia.

Once the stations in Andalusia were selected, their locations on the map of Andalusia were determined. Each location was compared with that of the 
Andalusian municipalities, obtained from SIMA (2020). The QGIS program (2019) was used to determine which station corresponded with each municipality. In order to do this, stations selected for each municipality were those closer than $25 \mathrm{~km}$ from their town. When two or more stations met that requirement, the closest with more data was chosen. Figure 1 shows the data catchment areas of the meteorological stations. Red, green and blue points indicate the REA, AEMET and RAIF stations, the red circle being their respective data catchment area. Black points represent the towns of the municipalities. As can be seen, nearly all municipalities are under these data catchment areas.

Figure 1. Data catchment areas of the meteorological stations

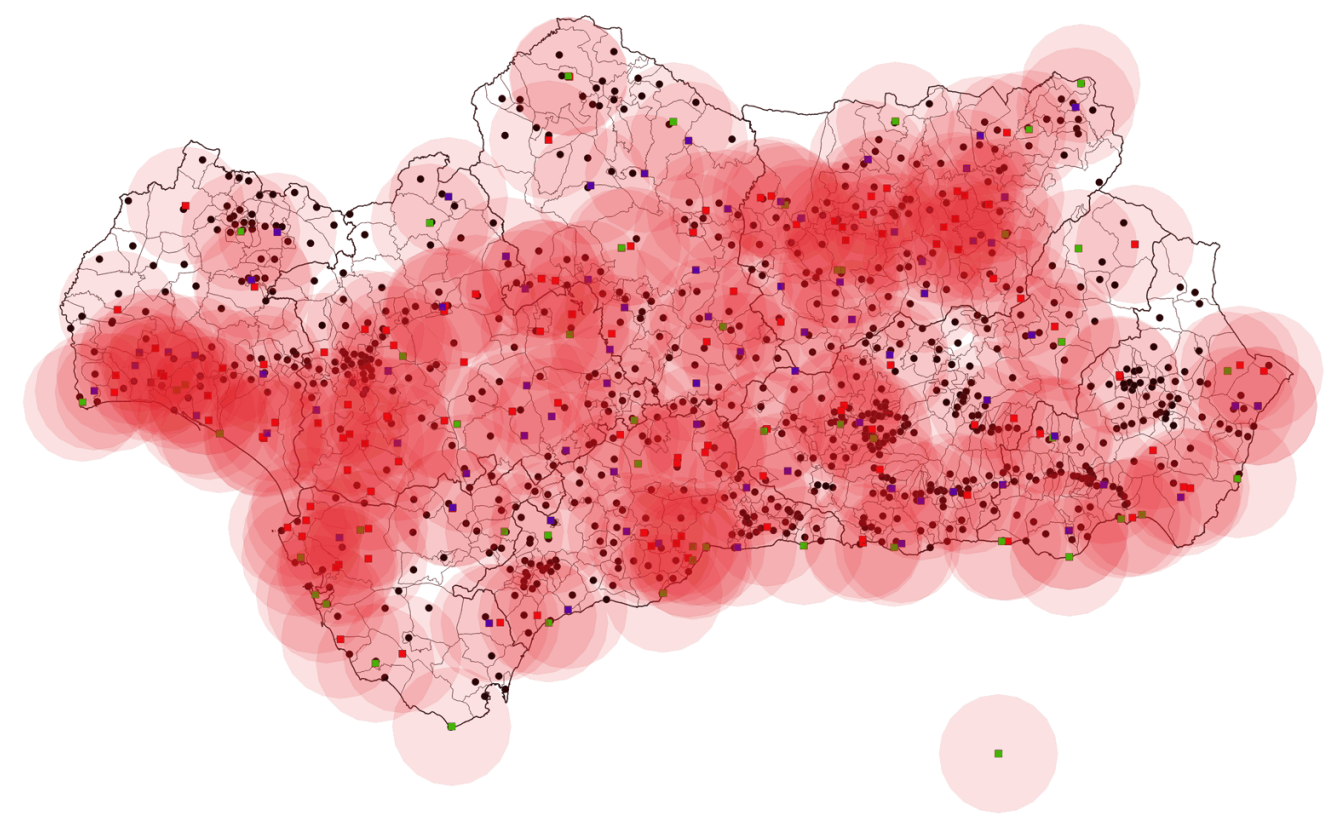

\subsection{Density data}

Finally, the population density of the territory is included in the model. This indicator has been used in previous studies referring to several municipalities as, for example, in Domene and Saurí (2006). Figures are expressed in terms of population on surface measured in persons per $\mathrm{Km}^{2}$, their values being converted into logarithms. 


\section{Methodology}

\subsection{Model specification}

In this paper, the long-run equilibrium relationship across residential electricity use, income, temperatures and density, is studied by using different panel data econometric procedures. With this aim, the following basic regression is developed,

$E_{i t}=f\left(Y_{i t}, H D D_{i t}, C D D_{i t}, d_{i t}\right)$

where $E$ is the residential electricity use per capita, $Y$ represents the declared income per capita, $H D D$ and $C D D$ refer to the temperature variables, $d$ is the population density, $i$ indicates the Andalusia municipalities, and $t$ is a time variable.

Two main considerations were taken into account when studying the previous regression. Firstly, as stated in the literature review section, a non-linear relationship between energy use (and residential energy use) and income, is observed in many previous studies ( Nguyen-Van, 2010; Sbia et al., 2017; Pablo-Romero and SánchezBraza, 2017, among others), giving rise to the Energy-EKC hypothesis (Dong and Hao, 2018). Therefore, the per capita income variables in squared and cubed terms were taken into account when specifying the residential electricity consumption function.

Secondly, temperature effects on residential energy consumption were also considered non-linear. Most previous studies show that temperature effects on residential energy consumption vary, according to the heating or cooling needs, and include two temperature variables in the equation model: the CDD and HDD variables (as in Tilov et al. 2020). Beyond these considerations, other authors (such as Pablo-Romero et al. 2019) also consider that each of these two variables may, in 
turn, have a non-linear effect on electricity consumption, and include CDD, HDD and their respective squared expressions in their studies. Therefore, in this study, the squared CDD and HDD variables are also introduced in the model. Thus, as stated in Chang et al. (2016), including these squared variables allows it to be taken into account that the residential electricity consumption variation because of temperature changes may depend on the temperature level.

Taking into account the above considerations, and with the aim of comparing the results, three residential electricity consumption function specifications are estimated:

$\ln E_{i t}=A_{i}+\delta_{1}$ trend $+\delta_{2}$ trend $^{2}+\beta_{1} \ln Y_{i t}+\beta_{4} \ln C D D_{i t}+\beta_{6} \ln H D D_{i t}+\beta_{7} d_{i t}+e_{i t}$

$\ln E_{i t}=A_{i}+\delta_{1}$ trend $+\delta_{2}$ trend $^{2}+\beta_{1} \ln Y_{i t}+\beta_{2}\left(\ln Y_{i t}\right)^{2}+\beta_{3}\left(\ln Y_{i t}\right)^{3}+\beta_{4} \ln C D D_{i t}+\beta_{6} \ln H D D_{i t}+\beta_{7} d_{i t}+$

$e_{i t}$

$\ln E_{i t}=A_{i}+\delta_{1}$ trend $+\delta_{2}$ trend $^{2}+\beta_{1} \ln Y_{i t}+\beta_{2}\left(\ln Y_{i t}\right)^{2}+\beta_{3}\left(\ln Y_{i t}\right)^{3}+\beta_{4} \ln C D D_{i t}+\beta_{5}\left(\ln C D D_{i t}\right)^{2}+$

$\beta_{6} \ln H D D_{i t}+\beta_{6}\left(\ln H D D_{i t}\right)^{2}+\beta_{7} d_{i t}+e_{i t}$

where trend indicates a time trend and $e$ is the error term.

The inclusion of the squared and cubic income values in equations [3] and [4], allows the Energy-EKC hypothesis to be studied by analyzing the sign of the $\beta 1, \beta 2$ and $\beta 3$ estimated coefficients, as in Dinda (2004). In the same way, the inclusion of the squared CDD and HDD values in equation [4] allows to study the temperature non-linearity effects on residential electricity consumption, by analyzing the sign of the $\beta 4$ and $\beta 5$ and the $\beta 6$ and $\beta 7$ coefficients, respectively.

\subsection{Econometric procedure}

Prior to estimating these functions, the multicollinearity was studied by using the variance inflation factors (VIF). The results presented in Column 2 of Table 1, show 
that multicollinearity is present. Following Pablo-Romero et al. (2019), all data were transformed into deviations from the geometric mean of the sample, removing this problem (Column 3 in Table 1). The variables change implies that $\beta 1, \beta 4$ and $\beta 6$ coefficients now show the residential electricity use elasticity, with respect to income, CDD and HDD at the sample center point, respectively.

Table 1 VIF results

\begin{tabular}{ccc}
\hline Variables & VIF & VIF \\
& (variables) & (transformed variables) \\
\hline $\mathrm{Y}$ & 104373.97 & 2.96 \\
$\mathrm{Y}^{2}$ & 431926.10 & 1.36 \\
$\mathrm{Y}^{3}$ & 112322.76 & 2.55 \\
$\mathrm{HDD}$ & 538.36 & 2.53 \\
$\mathrm{HDD}$ & 550.90 & 1.95 \\
$\mathrm{CDD}$ & 174.78 & 2.29 \\
$\mathrm{CDD}$ & 173.89 & 1.60 \\
$\mathrm{~d}$ & 1.86 & 1.86 \\
\hline Mean VIF & 81257.83 & 2.14 \\
\hline
\end{tabular}

Once the transformation of all variables has been undertaken, the stochastic nature of the variables needs to be examined to properly estimate equations [2], [3] and [4]. Firstly, the Pesaran cross-sectional dependence (CD) test (2004) was performed, where the null hypothesis is cross-sectional independence. The results (Table 2) show that this hypothesis is rejected in all cases.

Table 2. Pesaran CD test.

Variables CD test




\begin{tabular}{cc}
\hline $\mathrm{E}$ & $1097.70 * * *$ \\
$\mathrm{Y}$ & $231.94 * * *$ \\
$\mathrm{Y}^{2}$ & $954.97 * * *$ \\
$\mathrm{Y}^{3}$ & $1037.11 * * *$ \\
$\mathrm{HDD}$ & $146.34 * * *$ \\
$\mathrm{HDD}$ & $1010.88 * * *$ \\
$\mathrm{CDD}$ & $89.82 * * *$ \\
$\mathrm{CDD}^{2}$ & $215.63 * * *$ \\
\hline N & \\
\hline Note: & \\
\hline denotes significance at the $1 \%$ level
\end{tabular}

Secondly, the cross-sectionally augmented Im, Pesaran and Shin tests-CIPS (Pesaran, 2007) were performed. As can be inferred from Table 3, the non-stationary null hypothesis is rejected for all of the variables (at the 5\% significance level). Thus, all of the considered series are stationary in the levels.

Table 3. CIPS test

\begin{tabular}{ccc}
\hline Variables & \multicolumn{2}{l}{ Level } \\
\hline & Intercept & Intercept and trend \\
\hline $\mathrm{Y}$ & $-2.150^{* *}$ & $-10.203^{* * *}$ \\
$\mathrm{Y}^{2}$ & $-2.279^{* *}$ & $-3.311^{* * *}$ \\
$\mathrm{Y}^{3}$ & $-11.373^{* * *}$ & $-12.277^{* * *}$ \\
$\mathrm{HDD}^{*}$ & $-21.833^{* * *}$ & $-13.478^{* * *}$ \\
$\mathrm{HDD}^{2}$ & $-28.538^{* * *}$ & $-13.330^{* * *}$ \\
$\mathrm{CDD}^{* * *}$ & $-9.088^{* * *}$ & $-7.342^{* * *}$
\end{tabular}




\begin{tabular}{ccc}
$\mathrm{CDD}^{2}$ & $-25.804^{* * *}$ & $-18.506^{* * *}$ \\
$\mathrm{~d}$ & $-1.828^{* *}$ & $-7.139^{* * *}$ \\
\hline
\end{tabular}

Note: ${ }^{* *}$ denotes significance at the $1 \%$ level, ${ }^{* *}$ at the $5 \%$ level.

Finally, the Hausman test and the modified Wald test proposed in Greene (2000) were performed. The results, shown in Table 4, indicate that the fixed effects model is adequate and that there is presence of heteroskedasticity.

Table 4. Fixed effect and heteroskedasticity tests

\begin{tabular}{cc}
\hline & Test results \\
\hline Hausman test & $\operatorname{chi} 2(23)$ \\
& $1825.93^{* * *}$ \\
heteroskedasticity & $\operatorname{chi} 2(513)=$ \\
& $3.8 \mathrm{e}+05^{* * *}$ \\
\hline
\end{tabular}

Note: ${ }^{* * *}$ denotes significance at the $1 \%$ level

Taking into account the previous results, the Fixed Effects Ordinary Least Squares with Driscoll and Kraay standard errors (FE-OLS-DK) is used, as this technique is robust to cross-sectional dependence and heteroskedasticity (Hoechle, 2007).

Finally, a panel quantile regression technique was performed to estimate equations [2] to [4]. Generally, empirical research uses quantile regressions if the variables have potentially dissimilar effects at different points in the dependent variable conditional distribution. As stated in Bitler et al. (2006), these effects are not captured when using traditional regression models (Hübler, 2017), as they are based on the mean. On the contrary, the quantile regression models are based on the median, being robust in the presence of outliers (Koenker and Hallock, 2001). Thus, the quantile regression method is more efficient than the OLS method, when the residuals do not follow a normal distribution (Niu et al., 2016). 
This method has already been performed in energy and environmental studies, although it is still quite limited, due to its novelty. Some examples of the growing use of this method are the studies by Kaza (2010), Niu et al. (2016), Chen and Lei (2018) and Sarkodie and Strezov (2019). More recently, this method has also been used when testing the EKC hypothesis, as in Albulescu et al. (2019), Ike et al. (2020), Salman et al. (2019), and Zhou and Li (2019), with different results being found for different quantile emissions levels in all studies. Focusing on residential electricity consumption, this method has also been used when analyzing household electricity demand. Likewise, the study by Tilov et al. (2020), also finds different temperature effects on electricity demand depending on the quantile level.

Taking into account these previous studies, the quantile regression analysis method is also performed in this paper, to allow an answer to be found to the question of whether an explanatory variable (income, temperatures or density) has different impacts, across conditional quantiles of residential electricity use. The results may provide a more complete picture of the relationship between the electricity use and the set of covariates under study.

The panel quantile regression was first used by Koenker and Bassett (1978). Nevertheless, this general quantile regression does not consider the unobserved individual heterogeneity. Thus, and taking into account the test results shown in Table 4, a FE model is used. In this paper, the recent Method of Moments Quantile Regression (MMQR) with FE, by Machado and Silva (2019), is performed. This method, as stated in Machado and Silva (2019), is especially attractive when estimating regression quantiles, including individual effects, because it is very easy to implement, allowing the entire distribution to be affected by individual effects, instead of changing the means as in the methods used by Koenker (2004) and Canay 


\section{Results and discussion}

\subsection{FE-OLS-DK results and discussion}

The results of estimating [2], [3] and [4] by FE-OLS-DK are shown in Columns $a$ to $c$ in Table 5, respectively. As can be observed, the estimated coefficients are significant. The coefficients related to $Y$ shown in these columns are positive and significant. Consequently, in the central point of the sample, the elasticity respect to income is positive. In addition, the Column $b$ and $c$ results related to $Y^{2}$ and $Y^{3}$ are compatible with an inverted $\mathrm{N}$ shaped relationship, between income and residential electricity consumption. Therefore, for higher income levels, the EKC hypothesis is supported. Regarding the temperature variables, CDD and HDD variables are significant and positive, indicating that increasing temperature values above $22^{\circ} \mathrm{C}$, and decreasing temperatures below $15^{\circ} \mathrm{C}$, increase the residential electricity consumption in the Andalusian municipalities. Beyond this positive relationship, Column c results also indicate that these relationships are progressively growing in both cases. Nevertheless, it is worth noting that coefficients linked to HDD are higher than those related to $\mathrm{CDD}$, therefore the more extreme cold has a greater impact on residential energy use in Andalusia than the extreme heat. Finally, the results also show a negative effect of population density on the residential energy consumption.

Table 5 Estimate results by using FE-OLS-DK

FE-OLS-DK FE-OLS-DK $\quad$ FE-OLS-DK




\begin{tabular}{|c|c|c|c|}
\hline & Equation [2] & Equation [3] & Equation [4] \\
\hline & $\mathbf{a}$ & $\mathbf{b}$ & c \\
\hline \multirow{2}{*}{$\mathrm{Y}$} & $0.318 * * *$ & $0.364 * * *$ & $0.368 * * *$ \\
\hline & $(0.025)$ & $(0.023)$ & $(0.024)$ \\
\hline \multirow{2}{*}{$Y^{2}$} & & $0.039 * *$ & $0.040 * *$ \\
\hline & & $(0.018)$ & $(0.018)$ \\
\hline \multirow{2}{*}{$\mathrm{Y}^{3}$} & & $-0.043 * * *$ & $-0.044 * * *$ \\
\hline & - & $(0.009)$ & $(0.009)$ \\
\hline \multirow{2}{*}{ CDD } & $0.034 * * *$ & $0.035 * * *$ & $0.042 * * *$ \\
\hline & $(0.006)$ & $(0.006)$ & $(0.008)$ \\
\hline \multirow[t]{2}{*}{$\mathrm{CDD}^{2}$} & & & $0.007 * *$ \\
\hline & - & - & \\
\hline \multirow{2}{*}{ HDD } & $0.064 * * *$ & $0.070 * * *$ & $0.099 * * *$ \\
\hline & $(0.011)$ & $(0.010)$ & $(0.013)$ \\
\hline \multirow[b]{2}{*}{$\mathrm{HDD}^{2}$} & & & $0.034 * * *$ \\
\hline & - & - & $(0.007)$ \\
\hline \multirow{2}{*}{ d } & $-0.394 * * *$ & $-0.414 * * *$ & $-0.414 * * *$ \\
\hline & $(0.041)$ & $(0.045)$ & $(0.045)$ \\
\hline
\end{tabular}

In order to detail these income effects, the elasticity with respect to income have been calculated by using the estimated coefficients presented in Column c. Figure 2 illustrates the elasticity linked to per capita income values (in logs).

Figure 2. Elasticity of residential electricity use with respect to income related to income levels (in per capita terms). 


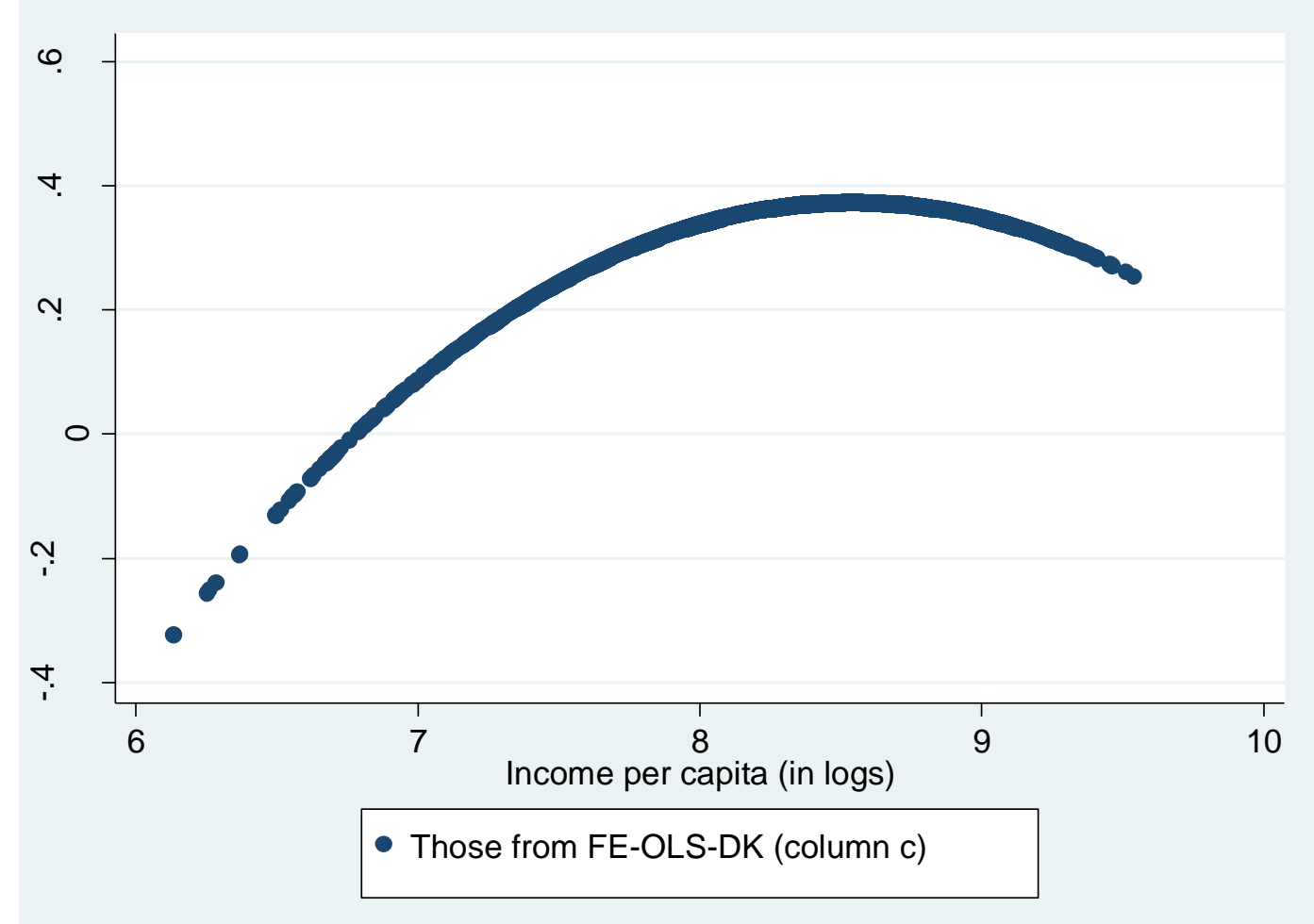

The elasticity values grow with income up to a maximum point, and from this point, the elasticity tends to decrease. Nevertheless, although this is compatible with the inverted $\mathrm{U}$, part of the inverted $\mathrm{N}$ curve, the maximum value of the inverted $\mathrm{U}$ is not reached. Therefore, the elasticity does not return to be negative. The income increase has positive effects on residential electricity consumption (or at least reduces the negative impact observed in low income levels that have negative elasticities). This means certain efficiency gains can be observed in municipalities with higher income levels, without those efficiency gains being large enough to reduce the electricity consumption of the sector.

\subsection{Quantile regression estimate results and discussion}

Before performing the panel quantile regression method, it is worth checking whether the residuals from FE-OLS regression are normally distributed. Two tests have been used to test the normal distribution of the residuals, as in Salman et al. (2019): the Shapiro-Francia (Royston, 1983) and the Shapiro-Wilk (Royston, 1992) 
tests. As shown in Table 6, the null hypothesis of normally distributed data is rejected by both tests. Thus, residuals are not normally distributed, and previous estimates might present biases, so the quantile regression may be adequate for estimating equations [2] to [4].

Table 6. Shapiro-Wilk W and Shapiro-Francia W' tests

\begin{tabular}{ccc}
\hline & $\mathbf{W}$ & $\mathbf{W}^{\prime}$ \\
\hline OLS-FE [4] & $0.977^{* * *}$ & $0.977^{* * *}$ \\
OLS-FE [4] & & \\
first diff & $0.993^{* * *}$ & $0.993^{* * *}$ \\
PCSE [4] & & \\
first diff & $0.984^{* * *}$ & $0.984^{* * *}$ \\
\hline
\end{tabular}

Note: ${ }^{* *}$ denotes significance at the $1 \%$ level,

The quantile regression method offers a complete picture of impacts of independent variables on the residential electricity consumption in Andalusia at various quantile levels. In order to obtain this detailed analysis, the quantile levels selected in this paper are nine $\left(10^{\text {th }}\right.$ to 90 th). Table 7 displays the equation [4] quantile regression estimate results obtained by using the fixed effects MMQR method. Equation [2] and [3] estimate results display similar coefficient values.

Firstly, it is worth highlighting that the results are generally quite significant, tending to vary between quantiles. Therefore, the model captures differences that are not shown in the previous estimates shown in Table 5. To facilitate the main differences observed, Figure 2 shows the values of coefficients by quantile for all variables (QR in Figure 2) and their respective confidence intervals (CI1 and CI2). The values of coefficients estimated from FE-OLS-DK have also been incorporated 
into each graph of Figure 3. In general, it can be observed that the OLS-FE-DK estimated coefficient values are quite similar to the fifth quantile value. Therefore, the values obtained by using the quantile regression method are consistent with those obtained by the FE-OLS-DK model

Table 7. Method of moments quantile regression estimate results

\begin{tabular}{|c|c|c|c|c|c|c|c|c|c|}
\hline & Eq.[4] & Eq.[4] & Eq.[4] & Eq.[4] & Eq. [4] & Eq. [4] & Eq. [4] & Eq.[4] & Eq. [4] \\
\hline & $q(0.1)$ & $q(0.2)$ & $q(0.3)$ & $q(0.4)$ & $q(0.5)$ & $q(0.6)$ & $q(0.7)$ & $q(0.8)$ & $q(0.9)$ \\
\hline \multirow[t]{2}{*}{$\bar{Y}$} & $0.320 * * *$ & 0.332 *** & $0.342 * * *$ & $0.342 * * *$ & $0.365^{* * *}$ & $0.378 * * *$ & 0.390 *** & $0.403^{* * *}$ & $0.422 * * *$ \\
\hline & $(0.025)$ & $(0.021)$ & $(0.018)$ & $(0.018)$ & $(0.015)$ & $(0.017)$ & $(0.020)$ & $(0.025)$ & $(0.032)$ \\
\hline \multirow[t]{2}{*}{$\mathrm{Y}^{2}$} & 0.001 & 0.011 & $0.019^{*}$ & $0.028 * *$ & $0.037 * * *$ & $0.048 * * *$ & $0.058^{* * *}$ & $0.069 * * *$ & $0.084 * * *$ \\
\hline & $(0.019)$ & $(0.015)$ & $(0.012)$ & (0.008) & $(0.011)$ & $(0.012)$ & $(0.015)$ & $(0.018)$ & $(0.024)$ \\
\hline \multirow[t]{2}{*}{$\mathrm{Y}^{3}$} & $-0.049 * * *$ & $-0.048 * * *$ & $-0.047 * * *$ & $-0.046^{* * *}$ & $-0.044 * * *$ & $-0.043 * * *$ & $-0.042 * * *$ & $-0.040 * * *$ & $-0.038 * *$ \\
\hline & $(0.012)$ & $(0.015)$ & $(0.009)$ & (0.008) & (0.007) & (0.008) & $(0.010)$ & $(0.012)$ & $(0.016)$ \\
\hline \multirow[t]{2}{*}{ CDD } & $0.081 * * *$ & $0.071^{*} * *$ & $0.063 * * *$ & $0.055^{* * *} *$ & $0.045^{* * *}$ & $0.035^{* * *}$ & $0.025 * *$ & 0.014 & 0.000 \\
\hline & $(0.014)$ & $(0.011)$ & $(0.010)$ & (0.008) & (0.008) & $(0.009)$ & $(0.011)$ & $(0.013)$ & $(0.017)$ \\
\hline \multirow[t]{2}{*}{$\mathrm{CDD}^{2}$} & 0.017 *** & $0.015^{* *}$ & $0.012 * *$ & $0.010^{* *}$ & $0.007 *$ & 0.004 & 0.002 & 0.001 & -0.004 \\
\hline & $(0.007)$ & $(0.005)$ & $(0.005)$ & (0.004) & (0.004) & $(0.004)$ & $(0.005)$ & $(0.006)$ & $(0.009)$ \\
\hline \multirow[t]{2}{*}{ HDD } & $0.141 * * *$ & $0.130 * * *$ & $0.121 * * *$ & $0.112 * * *$ & $0.102 * * *$ & $0.090 * * *$ & $0.080 * * *$ & $0.068 * * *$ & $0.052 *$ \\
\hline & $(0.025)$ & $(0.018)$ & $(0.016)$ & $(0.014)$ & $(0.013)$ & $(0.015)$ & $(0.018)$ & $(0.022)$ & $(0.028)$ \\
\hline \multirow[t]{2}{*}{$\mathrm{HDD}^{2}$} & $0.059 * * *$ & $0.053^{* * *}$ & $0.047 * * *$ & $0.043 * * *$ & $0.036 * * *$ & $0.029 * * *$ & $0.022^{* * *}$ & 0.015 & 0.005 \\
\hline & $(0.012)$ & $(0.010)$ & $(0.008)$ & $(0.007)$ & $(0.007)$ & $(0.008)$ & $(0.009)$ & $(0.012)$ & $(0.015)$ \\
\hline \multirow[t]{2}{*}{$\mathrm{d}$} & $-0.361 * * *$ & $-0.376^{* * *}$ & $-0.386 * * *$ & $-0.397 * * *$ & $-0.410 * * *$ & $-0.424 * * *$ & $-0.438 * * *$ & $-0.452 * * *$ & $-0.471 * * *$ \\
\hline & $(0.032)$ & $(0.026)$ & $(0.022)$ & $(0.020)$ & (0.019) & $(0.021)$ & $(0.025)$ & $(0.031)$ & $(0.008)$ \\
\hline
\end{tabular}


Figure 3. Estimated coefficients by method of moments quantile regression
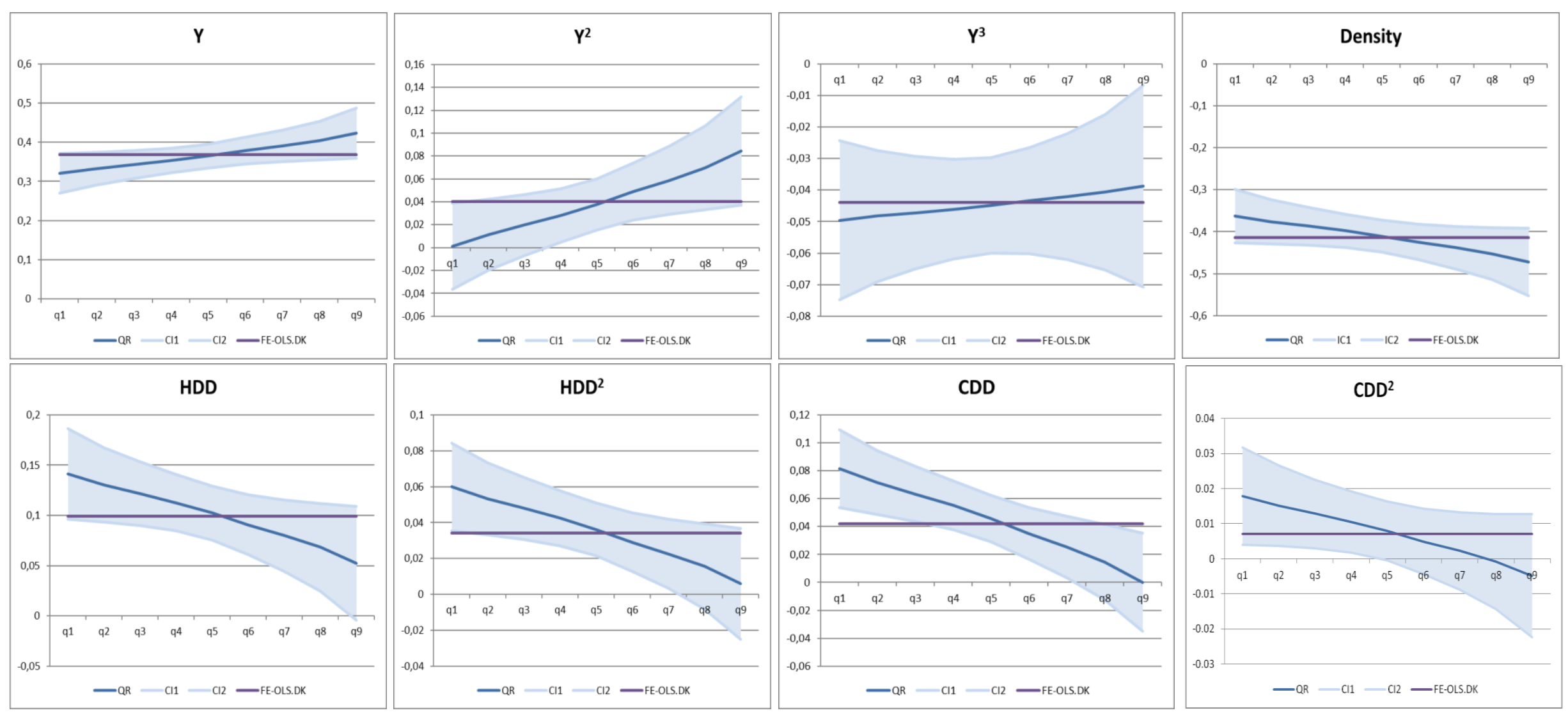
Regarding the coefficients linked to the income variables, Table 7 and Figure 3 show that the coefficients for the income, and square and cubic income, tend to increase with the quantile (the cubic value becomes less negative). The coefficient associated to $\mathrm{Y}$ tends to increase from 0.32 to 0.43 with the quantile. These elasticity values are quite similar to those observed in the study by Tilov et al. (2019), who also found elasticity values increasing with the quantile. Thus, the response of the residential electricity use to income, tends to increase as the quantile grows, that is, as the electricity consumption grows in per capita terms.

The coefficients linked to squared and cubic income variables are positive and negative, respectively, for all quantiles. Therefore, for all quantiles, an inverse $\mathrm{N}$ relationship is observed between the mentioned variables. As the cubic income variable coefficient is significant and negative for all quantiles, the elasticity with respect to income tends to decrease as income grows, from a threshold point. Nevertheless, this does not mean that negative elasticity values are obtained, only that these values tend to decrease, from a determined point. In fact, the turning point of the inverted $\mathrm{U}$ part of the inverse $\mathrm{N}$ curve is not reached for the municipalities' income values. These results are also similar with those obtained in the Tilov et al. (2019) study. The authors observe inverse $\mathrm{N}$ relationships between income and energy use, without achieving negative income elasticity values, that is, rejecting the Energy-EKC hypothesis. Therefore, promoting economic growth is not enough to control residential electricity consumption.

Additionally, it should be noted that the three income coefficients tend to increase with the quantile. The inverse $\mathrm{N}$ shape tends to be more marked, and less soft for higher quantiles, therefore, the increasing and decreasing sections of the curve have greater slopes. Since almost all the observations are related to the increasing stretch 
of the inverse N-shaped curve (positive elasticities, as previously seen in Figure 2), as the quantile increases, the residential electricity consumption response to income becomes more pronounced (the elasticity curve observed in Figure 2 has less curvature, coming closer to a straight line). There is a greater response to income variations in municipalities with higher residential electricity consumption. In the municipalities with the highest residential electricity consumption, the percentage increase in income produces greater percentage increases in electricity consumption, thus gaining inefficiency. Therefore, there is a greater coupling between income and consumption of residential electricity in municipalities with greater electricity consumption. Thus, it may be appropriate to promote efficiency measures in all municipalities, but especially in those with the greatest per capita residential electricity consumption, as these efficiency gains will have higher benefits for the whole region of Andalusia.

Regarding the temperature variables, different values are also observed by quantiles. The CDD variable is always positive, but only significant up to the 80 th percentile. Likewise, the coefficient value tends to decrease as the quantile increases. Additionally, when observing the squared CDD variable coefficient value, it can be seen that the positive values obtained also tend to decrease as the quantile increases, though not being significant from the 60th percentile. Therefore, as temperature increases, the energy consumption is progressively higher in all cases. However, those municipalities with lower residential electricity consumption, in per capita terms, have higher sensitivity to higher temperatures, while those with higher residential electricity consumption, seem to appear to be not significantly sensitive to rising temperatures above $22^{\circ} \mathrm{C}$. These results seem to differ from those obtained by Romero-Jordan et al. (2016), for Spanish household electricity demand in the 
2006-2012 period, who find increasing CDD coefficients with quantile increase. However, the CDD variable is for $18^{\circ} \mathrm{C}$ instead of $22^{\circ} \mathrm{C}$, and no squared value is included in the model. Even taking into account these modeling differences, how can the fact that CDD variables effects are lower in municipalities with higher electricity consumption be explained? It may be that those municipalities with lower electricity consumption per capita tend not to use their cooling devices, until the temperature is very high, only changing their consumption pattern in these cases. Meanwhile, those with high levels of energy consumption may also use their devices at lower temperatures, thus causing them to be unaffected, or at least, not so affected by rising temperatures.

Something similar happens with the HDD variable. The values of coefficients are positive and tend to reduce their values as the quantile increases. Nevertheless, in this case, the coefficient for the HDD variable is always significant, and only the coefficient for the squared HDD becomes non-significant, from the 80th percentile. In this way, it is the municipalities with the lowest electricity consumption in the residential sector that are most affected by the decrease in temperatures below $15^{\circ} \mathrm{C}$. Again, it could be thought that the consumption of these municipalities is lower because they only use their heating devices when the temperature is very low.

There may be indications that municipalities with lower residential electricity consumption use their devices more efficiently. Several reasons can induce this behavior. Among them, it is possible to consider the lower use of the devices for income reasons, or a greater awareness of the energy saving of certain municipalities. An extension of this study can then come hand in hand with the analysis of subsamples, divided by various concepts, such as income.

It is also worth noting that coefficients linked to HDD are higher than those related 
to $\mathrm{CDD}$, so that those municipalities with lower temperatures tend to have higher residential energy use. The results are similar to previous results related to country studies within Europe, as for example, in Borozan (2018 and 2019).

Finally, the results also reveal that the population density has a negative impact on the residential electricity use in the Andalusian municipalities. In this case, all quantile coefficients are negative and significant, their absolute value being higher in those municipalities with higher residential electricity consumption. A percentage increase in population density has higher negative impacts on municipalities with higher electricity consumption.

\section{Conclusion}

The increased use of renewable energy in electricity generation has not been sufficient to reduce the associated emissions, as the electricity demand increase has been higher than the increased use of renewable energy in the sector. Therefore, analyses related to the evolution of electricity consumption are necessary to adapt adequate energy policies to emissions reductions. This paper analyzes the electricity demand in the residential sector in Andalusia (Spain), during the period 2001-2016, by considering the non-linear income and temperature effects. To this end, panel data OLS and quantile regression analysis methods have been undertaken, to offer a complete picture of the relationship between the studied variables.

All the regression methods used have shown similar results, although some specific questions are raised from these methods. Firstly, the coefficient link to the income variable is positive in all estimates. Additionally, the positive squared income variable coefficient and negative cubic income variable, support inverted $\mathrm{N}$ shaped relationships between income and residential electricity use. Regarding the results of the non-quantile regressions method, the calculated elasticities, with respect to 
income, reveal that, although data are compatible with the inverted $U$ part of the inverted $\mathrm{N}$ curve, the maximum value of the inverted $\mathrm{U}$ is not reached. Therefore, certain efficiency gains may be observed in municipalities with higher income levels, without those efficiency gains being sufficient to reduce the residential electricity use.

Regarding the quantile regression results, all the coefficients related to income tend to increase with the quantile. Thus, the response of the residential electricity use to income tends to increase, as the per capita electricity use grows. Likewise, an inverse $\mathrm{N}$ relationship is observed between residential electricity use and income. Nevertheless, as in the OLS results, the turning point of the inverted U part of the inverse $\mathrm{N}$ curve is not reached for the income values of the municipalities. Therefore, the Energy-EKC hypothesis is rejected, and promoting economic growth is not sufficient to control electricity consumption. The results reveal that, in the municipalities with the highest residential electricity use, the percentage increase in income produces greater percentage increases in electricity consumption, thus gaining inefficiency. Thus, it could be appropriate to promote efficiency measures in all municipalities, but especially in those with the greatest per capita residential electricity consumption, as these efficiency gains will have higher benefits for the whole Andalusia region.

Regarding the temperature variables, for all estimates, it is observed that increasing temperature values above $22^{\circ} \mathrm{C}$, and decreasing temperatures below $15^{\circ} \mathrm{C}$, increase the residential electricity consumption in the Andalusia municipalities, with a progressively growing relationship, in both cases. Likewise, it is also observed that the more extreme cold has a greater impact on residential energy use in Andalusia than the extreme heat. 
Through quantiles, differences are observed in the temperature coefficients. The CDD and HDD coefficient values decrease as the quantile increases. In this way, the municipalities with the lowest residential electricity consumption are most affected, by the decrease in temperature below $15^{\circ} \mathrm{C}$, and by the increase in temperature, above $22^{\circ} \mathrm{C}$. Thus, municipalities with lower residential electricity consumption use their devices more efficiently. An extension of this study may be desirable to determine the reasons for this behavior. In our opinion, this may be related to the fact that municipalities, with less residential energy consumption, only use their devices when temperatures are extreme, while in the others, they could be being used for less extreme temperature values.

Finally, the results also reveal that the population density has a negative effect on residential electricity use in the Andalusian municipalities, being higher in those municipalities with higher residential electricity consumption. That is, a percentage increase in population density has higher negative impacts on municipalities with higher electricity consumption.

\section{Acknowledgements}

The first author acknowledges the financial support received from the $\mathrm{I}+\mathrm{D}+\mathrm{i}$ FEDER Andalucía 2014-2020 Project of the Junta de Andalucía (US-1260925) and from the and Chair on Energy Environmental Economics sponsored by "Red Eléctrica de España" at the University of Seville

\section{References}


AEMET, 2020. Servicios Climáticos/Datos Climáticos. Ministerio para la Transición Ecológica y Reto Demográfico. http://www.aemet.es/es/ (accessed 28 February 2020).

Albulescu, C.T., Tiwari, A.K., Yoon, S.M., Kang, S.H., 2019. FDI, income, and environmental pollution in Latin America: Replication and extension using panel quantiles regression analysis. Energy Econ, 104504. https://doi.org/10.1016/ j.eneco .2019.104504.

Auffhammer, M., 2018. Climate Adaptive Response Estimation: Short And Long Run Impacts Of Climate Change On Residential Electricity and Natural Gas Consumption Using Big Data (Working Paper No. w24397). National Bureau of Economic Research. https://www.nber.org/papers/w24397.

Auffhammer, M., Mansur, E.T., 2014. Measuring climatic impacts on energy consumption: A review of the empirical literature. Energy Econ, 46, 522-530. https://doi.org/10.1016/j.eneco.2014.04.017.

Bitler, M.P., Gelbach, J.B., Hoynes, H.W., 2006. What mean impacts miss: Distributional effects of welfare reform experiments. Am Econ Rev, 96(4), 988-1012. https://www.aeaweb.org/articles?id=10.1257/aer.96.4.988.

Blázquez, L., Boogen, N., Filippini, M., 2013. Residential electricity demand in Spain: New empirical evidence using aggregate data. Energy Econ, 36, 648-657. https://doi.org/10.1016/j.eneco.2012.11.010.

Borozan, D., 2018. Efficiency of energy taxes and the validity of the residential electricity environmental Kuznets curve in the European Union. Sustainability, 10(7), 2464. https://doi.org/10.3390/su10072464.

Borozan, D., 2019. Unveiling the heterogeneous effect of energy taxes and income on 
residential energy consumption. Energy Policy, 129, 13-22. https://doi.org/ 10.1016/j.enpol.2019.01.069.

Boyd, G.A., 2014. Estimating the changes in the distribution of energy efficiency in the US automobile assembly industry. Energy Econ, 42, 81-87. https://doi.org/10.1016/j.eneco.2013.11.008.

Burke, M., Hsiang, S.M., Miguel, E., 2015. Global non-linear effect of temperature on economic production. Nature, 527(7577), 235-239. https://doi.org/10.1038/ $\underline{\text { nature } 15725 .}$

Cade, B.S., Noon, B.R., 2003. A gentle introduction to quantile regression for ecologists. Front Ecol Environ, 1(8), 412-420. https://doi.org/10.1890/15409295(2003)001[0412:AGITQR]2.0.CO;2.

Canay, I.A., 2011. A simple approach to quantile regression for panel data. Econom J, 14(3), 368-386. https://doi.org/10.1111/j.1368-423X.2011.00349.x.

Chang, Y., Kim, C. S., Miller, J. I., Park, J. Y., Park, S., 2016. A new approach to modeling the effects of temperature fluctuations on monthly electricity demand. Energy $\quad$ Economics, 60, 206-216. https://doi.org/10.1016/j.eneco.2016.09.016

Chen, W., Lei, Y., 2018. The impacts of renewable energy and technological innovation on environment-energy-growth nexus: new evidence from a panel $\begin{array}{llll}\text { quantile } & \text { regression. Renew. } & \text { Energy, 123, }\end{array}$ https://doi.org/10.1016/j.renene.2018 .02.026.

Dinda, S., 2004. Environmental Kuznets curve hypothesis: a survey. Ecol Econ, 49(4), 431-455. https://doi.org/10.1016/j.ecolecon.2004.02.011.

Domene, E., Saurí, D., 2006. Urbanisation and water consumption: Influencing factors 
in the metropolitan region of Barcelona. Urban Stud, 43(9), 1605-1623. https://doi.org/10.1080/00420980600749969.

Dong, X.Y., Hao, Y., 2018. Would income inequality affect electricity consumption? Evidence from China. Energy, 142, 215-227. https://doi.org/10.1016/j.energy 2017.10.027.

EIA, 2019. International Energy Outlook 2019 with projections to 2050 (2019) U.S. Energy Information Administration, Washington. https://www.eia.gov/outlooks/ ieo/pdf/ieo2019.pdf.

Eskeland, G.S., Mideksa, T.K., 2010. Electricity demand in a changing climate. Mitig Adapt Strateg Glob Chang, 15, 877-897. https://doi.org/10.1007/s11027-0109246-x.

European Environment Agency, 2017. Climate Change, Impacts and Vulnerability in Europe 2016, EEA Report No 1/2017. European Environment Agency, Luxembourg. https://www.eea.europa .eu/publications/climate-change-impactsand-vulnerability-2016/at_download /file.

Expósito, A., Pablo-Romero, M., Sánchez-Braza, A., 2019. Testing EKC for urban water use: empirical evidence at river basin scale from the Guadalquivir river, Spain. J. Water Resour. Plan. Manag., 145(4), 04019005. https://doi.org/10.1061/(ASCE) WR.1943-5452.0001052.

Fan, S., Hyndman, R.J., 2011. The price elasticity of electricity demand in South $\begin{array}{llll}\text { Australia. } & \text { Energy } & \text { 39licy, } & \text { 39(6), }\end{array}$ https://doi.org/10.1016/j.enpol.2011 .03.080. 
Fazeli, R., Davidsdottir, B., Hallgrimsson, J.H., 2016. Residential energy demand for space heating in the Nordic countries: Accounting for interfuel substitution. Renew. Sust. Energ. Rev., 57, 1210-1226. https://doi.org/10.1016/j . .rser.2015.12.184.

Greene, W., 2000. Econometric Analysis, fourth ed. Prentice Hall, Upper Saddle River, New Jersey.

Hoechle, D., 2007. Robust standard errors for panel regressions with cross-sectional dependence. The Stata Journal, 7(3), 281-312. https://doi.org/10.1177/15368 $\underline{67 X 0700700301 .}$

Hübler, M., 2017. The inequality-emissions nexus in the context of trade and development: a quantile regression approach. Ecol Econ, 134, 174-185. https://doi.org/10.1016/j.ecolecon.2016.12.015.

IEA, 2015. Energy and Climate Change. International Energy Agency, Paris. https://www.iea.org/reports/energy-and-climate-change

IEA, 2019. Global Energy \& CO2 Status Report-The Latest Trends in Energy and Emissions in 2018. International Energy Agency, Paris. https://www.iea.org /reports/global-energy-co2-status-report-2019.

Ike, G.N., Usman, O., Sarkodie, S.A., 2020. Testing the role of oil production in the environmental Kuznets curve of oil producing countries: New insights from Method of Moments Quantile Regression. Sci. Total Environ., 711, 135208. https://doi.org/10.1016/j.scitotenv.2019.135208.

IPCC, 2018. Global Warming of $1.5^{\circ} \mathrm{C}$. Intergovernmental Panel on Climate Change. https://www.ipcc.ch/sr15/.

Kaza, N., 2010. Understanding the spectrum of residential energy consumption: A 
quantile regression approach. Energy Policy, 38(11), 6574-6585. https://doi.org /10.1016/j.enpol.2010.06.028.

Koenker, R., 2004. Quantile regression for longitudinal data. J Multivar Anal, 91(1), 74-89. https://doi.org/10.1016/j.jmva.2004.05.006.

Koenker, R., Bassett Jr., G., 1978. Regression quantiles. Econometrica, 46(1), 33-50. https://doi.org/10.2307/1913643.

Koenker, R., Hallock, K.F., 2001. Quantile regression. J Econ Perspect, 15(4), 143156. https://doi.org/10.1257/jep.15.4.143.

Kraft, J., Kraft, A., 1978. Relationship between energy and GNP. J. Energy Dev., 3(2), 401-403. https://www.jstor.org/stable/24806805.

Labandeira, X., Labeaga, J. M., López-Otero, X., 2012. Estimation of elasticity price of electricity with incomplete information. Energy Econ, 34(3), 627-633. https://doi.org/10.1016/j.eneco.2011.03.008.

Labriet, M., Joshi, S.R., Kanadia, A., Edwards, N.R., Holden, P.B., 2013. Impacts of climate change on heating and cooling: a worldwide estimate from energy and macro-economic perspectives. In: SSES Annual Congress 2013. https://www.unine.ch/files/live/sites/irene/files/shared/documents/SSES/Joshi.p df.

Lenzen, M., Wier, M., Cohen, C., Hayami, H., Pachauri, S., Schaeffer, R., 2006. A comparative multivariate analysis of household energy requirements in Australia, Brazil, Denmark, India and Japan. Energy, 31(2-3), 181-207. https://doi.org/10.1016/j.energy.2005.01.009.

Machado, J.A., Silva, J.S., 2019. Quantiles via moments. J Econom, 213(1), 145-173. https://doi.org/10.1016/j.jeconom.2019.04.009. 
Ministerio de Medio Ambiente, 2006. Plan Nacional de Adaptación al Cambio Climático 2006-2020 (PNACC-1). Ministerio de Medio Ambiente, Madrid. https://www.miteco.gob.es /images/es/pna_v3_tcm7-12445_tcm30-70393.pdf.

Narayan, S., Doytch, N., 2017. An investigation of renewable and non-renewable energy consumption and economic growth nexus using industrial and residential energy consumption. Energy Econ, 68, 160-176. https://doi.org/10.1016/j.eneco.2016.07.002.

Nejat, P., Jomehzadeh, F., Taheri, M. M., Gohari, M., Majid, M.Z A., 2015. A global review of energy consumption, $\mathrm{CO} 2$ emissions and policy in the residential sector (with an overview of the top ten $\mathrm{CO} 2$ emitting countries). Renew. Sust. Energ. Rev., 43, 843-862. https://doi.org/10.1016/j.rser.2014.11.066.

Nguyen-Van, P., 2010. Energy consumption and income: A semiparametric panel data analysis. Energy Econ, 32(3), 557-563. https://doi.org/10.1016/j.eneco.2009 .08 .017 .

Nie, H.G., Kemp, R., Xu, J.H., Vasseur, V., Fan, Y., 2018. Drivers of urban and rural residential energy consumption in China from the perspectives of climate and economic effects. J. Clean. Prod., 172, 2954-2963. https://doi.org/10.1016 /j.jclepro.2017.11.117.

Niu, S., Jia, Y., Ye, L., Dai, R., Li, N., 2016. Does electricity consumption improve residential living status in less developed regions? An empirical analysis using the quantile regression approach. Energy, 95, 550-560. https://doi.org/10.1016/j .energy.2015.12.029.

Pablo-Romero, M.D.P., Pozo-Barajas, R., Sánchez-Braza, A., 2016. Analyzing the effects of Energy Action Plans on electricity consumption in Covenant of 
Mayors signatory municipalities in Andalusia. Energy Policy, 99, 12-26. https://doi.org /10.1016/j.enpol.2016.09.049.

Pablo-Romero, M.D.P., Pozo-Barajas, R., Sánchez-Rivas, J., 2019. Tourism and temperature effects on the electricity consumption of the hospitality sector. J. Clean. Prod., 240, 118168. https://doi.org/10.1016/j.jclepro.2019.118168.

Pablo-Romero, M.P., Sánchez-Braza, A., 2017. Residential energy environmental Kuznets curve in the EU-28. Energy, 125, 44-54. https://doi.org/10.1016 /j.energy.2017.02.091.

Pablo-Romero, M.P., Sánchez-Braza, A., Galyan, A., 2019. Relationship between economic growth and residential energy use in transition economies. Clim Dev, 11(4), 338-354. https://doi.org/10.1080/17565529.2018.1442789.

Pablo-Romero, M.P., Sánchez-Braza, A., Sánchez-Rivas, J., 2017. Relationships Between Hotel and Restaurant Electricity Consumption and Tourism in 11 European Union Countries. Sustainability, 9(11), 2109. https://doi.org/10.3390/ su9112109.

Pesaran, M.H., 2004. General diagnostic tests for cross section dependence in panels. Cambridge Working Papers WP0435, Faculty of Economics, University of Cambridge, Cambridge. https://doi.org/10.17863/CAM.5113.

Pesaran, M.H., 2007. A simple panel unit root test in the presence of cross-section dependence. J Appl Econ (Chichester Engl), 22(2), 265-312. https://doi.org/10 $.1002 /$ jae. 951 .

QGIS, 2019. QGIS Development Team. QGIS Geographic Information System. Open Source Geospatial Foundation. https://qgis.org/es/site/.

RAIF, 2020. Red de Alerta e Información Fitosanitaria. Consejería de Agricultura, 
Ganadería, Pesca y Desarrollo Sostenible, Junta de Andalucía. https://www.juntadeandalucia.es/organismos/agriculturaganaderiapescaydes arrollosostenible/servicios/sia/red-alerta-informacion-fitosanitaria/paginas/ red-alerta-informacion-datos.html (accessed 28 February 2020).

Raza, S.A., Shah, N., Khan, K.A., 2020. Residential energy environmental Kuznets curve in emerging economies: the role of economic growth, renewable energy consumption, and financial development. Environ Sci Pollut Res, 27, 56205629. https://doi.org/10.1007/s11356-019-06356-8.

REA, 2020. Red de Estaciones Agroclimáticas. Instituto de Investigación y Formación Agraria y Pesquera, Consejería de Agricultura, Ganadería, Pesca y Desarrollo Sostenible Junta de Andalucía. https://www.juntadeandalucia .es/agriculturaypesca/ifapa/ria/servlet/FrontController (accessed 28 February 2020).

Romero-Jordán, D., Del Río, P., Peñasco, C., 2016. An analysis of the welfare and distributive implications of factors influencing household electricity consumption. Energy Policy, 88, 361-370. https://doi.org/10.1016/j.enpol .2015 .09 .037 .

Romero-Jordán, D., Peñasco, C., Del Río, P., 2014. Analysing the determinants of household electricity demand in Spain. An econometric study. Int J Elec Power, 63, 950-961. https://doi.org/10.1016/j.ijepes.2014.06.005.

Royston, J.P., 1983. A Simple Method for Evaluating the Shapiro-Francia W' Test of Non-Normality. J. Royal Stat. Soc. D, 32(3), 297-300. https://doi.org/10.2307 $\underline{2987935 .}$. 
Royston, P., 1992. Approximating the Shapiro-Wilk W-test for non-normality. Stat Comput, 2, 117-119. https://doi.org/10.1007/BF01891203.

Salman, M., Long, X., Dauda, L., Mensah, C.N., Muhammad, S., 2019. Different impacts of export and import on carbon emissions across 7 ASEAN countries: A panel quantile regression approach. Sci. Total Environ., 686, 1019-1029. https://doi.org/10.1016/j.scitotenv.2019.06.019.

Sarkodie, S.A., Strezov, V., 2019. Effect of foreign direct investments, economic development and energy consumption on greenhouse gas emissions in developing countries. Sci. Total Environ., 646, 862-871. https://doi.org/10.1016/ j.scitotenv.2018.07.365.

Sbia, R., Shahbaz, M., Ozturk, I., 2017. Economic growth, financial development, urbanisation and electricity consumption nexus in UAE. Economic ResearchEkonomska Istraživanja, 30(1), 527-549. https://doi.org/10.1080/1331677X .2017 .1305792 .

Serrano, S., Ürge-Vorsatz, D., Barreneche, C., Palacios, A., Cabeza, L. F., 2017. Heating and cooling energy trends and drivers in Europe. Energy, 119, 425434. https://doi.org/10.1016/j.energy.2016.12.080.

SIMA, 2020. Sistema de Información Multiterritorial de Andalucía. Instituto de Estadística y Cartografía de Andalucía, Junta de Andalucía. https://www.juntadeandalucia.es/institutodeestadisticaycartografia/sima/index2. htm (accessed 28 February 2020).

Tiba, S., Omri, A., 2017. Literature survey on the relationships between energy, environment and economic growth. Renew. Sust. Energ. Rev., 69, 1129-1146. https://doi.org/10.1016/j.rser.2016.09.113. 
Tilov, I., Farsi, M., Volland, B., 2019. Interactions in Swiss households' energy demand: A holistic approach. Energy Policy, 128, 136-149. https://doi.org/10.1016/j .enpol.2018.12.027.

Tilov, I., Farsi, M., Volland, B., 2020. From frugal Jane to wasteful John: A quantile regression analysis of Swiss households' electricity demand. Energy Policy, 138, 111246. https://doi.org/10.1016/j.enpol.2020.111246.

Volland, B., 2017. The role of risk and trust attitudes in explaining residential energy demand: Evidence from the United Kingdom. Ecol Econ, 132, 14-30. https://doi.org/10.1016/j.ecolecon.2016.10.002.

Zhou, A., Li, J., 2019. Heterogeneous role of renewable energy consumption in economic growth and emissions reduction: evidence from a panel quantile regression. Environ Sci Pollut Res, 26, 22575-22595. https://doi.org/10.1007/ s11356-019-05447-w.

Zilio, M., Recalde, M., 2011. GDP and environment pressure: The role of energy in Latin America and the Caribbean. Energy Policy, 39(12), 7941-7949. https://doi.org/10.1016/j.enpol.2011.09.049. 